\title{
Fecal Immunochemical Test
}

National Cancer Institute

\section{Source}

National Cancer Institute. Fecal Immunochemical Test. NCI Thesaurus. Code C74538.

A fecal occult blood test that uses an immunological assay to detect hemoglobin in stool. 